\title{
A comparison of the earnings of specialist physicians and nurses before and after implementing the Iran's New Tariffs Book
}

\author{
Alireza Mazdaki ${ }^{1}$, Aziz Rezapour ${ }^{1}$, Samad Azari $^{1}$, Touraj Harati Khaliabad ${ }^{1}$, Masoud Behzadifar ${ }^{1}$, \\ Mahya Razi Moghadam ${ }^{1}$, Behzad Raei ${ }^{1}$, Mehdi Raadabadi ${ }^{1}$
}

Received: 12 Sep 2017

Published: 5 May 2018

\begin{abstract}
Background: The fair wage to specialist physicians and nurses can enhance their job motivation, quality of work, job satisfaction level, and improve the delivery of services to patients. The present study aimed to compare the proportion of changes in earnings of specialist physicians and nurses before and after implementing the Iran's New Tariffs Book and compare their average income with a number of selected countries.

Methods: This descriptive-analytical study was conducted cross-sectional in the hospitals affiliated to Iran University of Medical Sciences (IUMS) in 2016. Six months before and after the announcement and implementation of the Iran's New Tariffs Book, the relative values of healthcare services were compared. Study population included all specialist physicians and nurses working in the hospitals affiliated to IUMS. Sample size was determined by sampling formula.

Results: The proportion of changes in the income of medical specialists and nurses after establishing the book varied between $8 \%$ and $184 \%$. Based on our findings, the highest increases were observed in internal medicine $(184 \%)$, surgery $(160 \%)$, gastroenterology $(153 \%)$, and pediatrics $(120 \%)$, whereas, the lowest ones belonged to ophthalmology $(8 \%)$, emergency medicine $(11 \%)$, neurology $(24 \%)$ and anesthesia (32\%). Nurses' income was surged by $43 \%$.

Conclusion: Pursuant to the findings, the income belonged to all examined medical specialists and nursing groups has increased after implementing the Iran's New Tariffs Book. The result suggested that income differences among groups have been broadened after the implementation of the Book. There was a wide and significant difference in specialist physicians' income vis-à-vis nursing groups' income before and after establishing the New Book.
\end{abstract}

Keywords: Medical tariffs, Specialists, Nurses, Earnings, Iran

Copyright@ Iran University of Medical Sciences

Cite this article as: Mazdaki A, Rezapour A, Azari S, Harati Khaliabad T, Behzadifar M, Razi Moghadam M, Raei B, Raadabadi M. Comparison the earnings of specialists' physicians and nurses before and after implementing the Iran's New Tariffs Book. Med J Islam Repub Iran. 2018 (5 May);32:37. https://doi.org/10.14196/mjiri.32.37

\section{Introduction}

Broadly speaking, in all countries, governments irrespective of its domination and governance need to intervene in some issues (1). For the time being, in many countries, the health sector faces a great scarcity of the resource. People in poor countries tend to have less access to health services than those in better-off countries, and within countries, the poor have less access to health ser-

Corresponding author: Dr Samad Azari, samadazari1010@gmail.com

1. Health Management and Economics Research Center, Iran University of Medical Sciences, Tehran, Iran. vices (2). For this reason, a slight disturbance to the health economics of the countries can result in serious problems in the provision of health services. Because of market failure in health care systems, government intervention in the market is warranted. One of the epitomes of the government interventions for dealing with market failure is to set medical tariffs (3). Healthcare services tariffs are a

$\uparrow$ What is "already known” in this topic:

The fair wage to the specialist physicians and nurses can enhance their job motivation, quality of work, the level of job satisfaction and improve the delivery of services to patients.

$\rightarrow$ What this article adds:

In Iran, the proportion of changes in the income of medical specialists and nurses after establishing the Iran's New Tariffs Book varied between $8 \%$ and $184 \%$. The highest increases were observed in internal medicine (184\%), and the lowest ones belonged to ophthalmology $(8 \%)$. Nurses' income was surged by $43 \%$. 
matter of great importance regarding service type, the amount and coverage of service, health care resource allocation, the regulation of income and payment of insurance funds, as well as the access and utilization of medical services. The symmetry of health services to their real costs can result in that health settings are not adjusted to economic problems, private health centers respect tariffs enacted, and physicians are not paid for out of tariffs by the insured, in particular, low - income people are not deprived of having access to the services (4). As of September 2014, therefore, Ministry of Health and Medical Education (MoHME) announced and established the new book of health service value to close the gap between services tariffs and their real costs and to remove outlawed (under the table) payments.

Physicians and nurses are considered as the cornerstone of the healthcare system, and their capabilities have a profound impact on the quality and efficiency of the system. The fair payment of the salaries and perquisites of specialists and nurses can enhance job motivation, quality of work, the level of job satisfaction, and improve the delivery of services to patients. Working in a hospital calls for a teamwork. Team members, therefore, need to receive an equitable and not equal income. There exist factors such as qualifications, hard work, presence, work skills, occupational risk, stress, etc. that are used to determine the income of a job. Thus, equitable payment to team members is one of the crucial and determining factors to provide the best care for the patients $(4,5)$. Unreal tariffs and planned prices are the major challenges of Iranian health system. Some commentators believe that setting tariffs less than estimated cost price will lead to a gap in the incomes. In parallel with it, in our country, there is no mechanism to specify real revenue of various clinical sections. Additionally, the lack of proportionality among the tariffs of various service providers and specialties has caused concerns among health policy-makers (6). In recent years, having many new services added to the healthcare package in the country gave rise to providing major surgeries with new techniques or Para-clinical services by employing sophisticated and high-quality apparatus within a short time. It is essential that comparative value of health services is to be meshed with the aforementioned developments. So, in the tariffs book of the year 2014, the latest methods have been used for labeling health services (7). Studies indicate that in Iran a large part of the health sector's expenditures has been dedicated to pay for human resources, particularly physicians $(8,9)$. Improving payment mechanisms for physician services has received increasing attention in most countries. The broad goal of these mechanisms is to enhance health care quality, which is expected to improve long-term patients' health and reduce health care costs $(10,11)$. Increasing the income gap between physicians and nurses, the crucial differences between physicians 'and nurses' salaries, and the failure to set tariffs on nursing care are the cases that have been posed by the nursing and paramedical community after the implementation of the new tariff book. At the same time, one of the serious challenges of Iranian health ministry is a shortage of nursing staff $(13,14)$. The most recent attempt to deal with the tariff problem was to announce and implement the new book of health services value in 2014 . From the vantage point of many authors, it can remedy shortcomings of old tariff book, remove informal payments, and modify payment mechanisms. In a study carried out by Doshmangir et al., they examined the challenges and respective solutions of tariff system in Iranian health sector and classified them into 5 categories (3). Furthermore, Johansson and colleagues measured the pattern of nominal income changes in the US between 1998 and 2013 (15). Moreover, Barbara McPack et al. also studied the annual income of health sector employers in 4 countries including Burkina Faso, Ghana, Nigeria and Zambia in 2008 (16). Since there has not been any national study to compare the income of the various medical specialties and nurses, This study was carried out with three objectives: 1) to estimate average income gap between specialists physicians, 2) to estimate income gap between nursing groups, and 3) to compare income gap of Iranian health personnel with that of the chosen- mainly OECD- countries.

\section{Methods}

This descriptive-analytical study was conducted as cross-sectional in 2016. Six months before and after announcing and establishing the new book of the relative value of health services was determined as the study time period. Study community included all specialists and nurses working in the hospitals affiliated to Iran University of Medical Sciences (IUMS). This study approved by Health Management and Economics Research Center of IUMS with the code of ethics 163-28813. Given the sensitivity and confidentiality of human resources and income data, during all stages of this research the data was protected by the researchers.

All of the of specialists' physicians and nurses earnings data were provided to the research team in coordination with financial director of the University. Then, 10 samples from each specialists' physician groups and 100 samples from nursing groups from different hospitals were drawn randomly and their average incomes before and after the given time horizon were included in our analysis.

Data collection tool was a form including the data of incomes of specialist physicians and nursing groups. The collected data involved monthly income, the type of specialty, employment status, and faculty member full-time status, state of geographical location, job category, and work experience. In order to determine the proportion of earnings of specialist physicians and nurses during study time period and to compare them with selected countries, data analysis was done by descriptive statistics and presented in the form of tables. For this reason, initially, within-group comparisons in nursing groups and specialist physicians were made and then between-group comparison was undertaken to look into the income gap between nursing groups and specialist physicians before and after establishing the New Tariffs Book.

The sample size was determined by sampling formula, considering the average income gap between different physician groups estimated about 5,000,000 Rials (curren- 
cy of Iran), which is a minimum meaningful difference of incomes. The standard deviation (SD) for income gap between physicians groups was considered 25,000,000 Rials.

$$
\mathrm{N}_{\text {physicians }}=\frac{z_{\alpha}^{2} \cdot s_{d}^{2}}{d^{2}}=\frac{(1.96)^{2} \cdot(25000000)^{2}}{(5000000)^{2}}=96
$$

The meaningful income gap within nursing group was estimated 2,000,000 Rials, with standard deviation of $1,000,000$ Rials. A random sample is drawn from nurses working in hospitals affiliated to IUMS for this estimation.

$$
\mathrm{N}_{\text {nurse }}=\frac{z_{\alpha}^{2} \cdot s_{d}^{2}}{d^{2}}=\frac{(1.96)^{2} \cdot(10000000)^{2}}{(200000)^{2}}=96
$$

\section{Results}

The data in medical specialties and nursing group's income before and after establishing the New Tariffs Book are represented in Table 1.

As it is shown in the Table 1, the implementation of the new tariff book has drastically increased the income of all groups; this is the solution suggested by the health ministry to decline income gap and to remove informal payments. Moreover, the highest increases were in internal medicine $(184 \%)$, surgery $(160 \%)$, gastroenterology $(153 \%)$, pediatrics $(120 \%)$, whereas, the lowest increases belonged to ophthalmology $(8 \%)$, emergency medicine (11\%), neurology (24\%) and anesthesia (32\%). Nurses' income has surged by $43 \%$.

Specialist physicians-nursing group income ratio are shown in Table 2. As it can be seen, before the New Tariffs Book, the highest ratio of incomes received by specialists compared to nursing groups belonged to ophthalmic groups (23.7 times), anesthesia (18 times), and neurosurgery (16.6 times) respectively, whereas the lowest ratio was in orthopedic (1.8 times), pediatrics (3.2 times), and internal medicine (3.6 times). After the implementation of the New Tariffs Book, the highest ratio of incomes in specialist physician groups in comparison to nursing group belonged to surgery (20 times), ophthalmology (17.8 times), anesthesia (16 times) and neurosurgery (15.6 times) respectively. The lowest proportion in the period after the implementation of the book was for orthopedics (2.5 times), pediatrics (4.6 times), and emergency medicine (4.8 times). It can be concluded that before the implementation of the New Tariffs Book, the mean income of specialist physicians was 9.8 times of nurses' income. However, this figure has increased to 10.8 times after establishing the new tariff values.

As evident in Table 3, among the specialties, the highest and the lowest income belong to orthopedics and pediatrics respectively. The nursing group, accounts for $50 \%$ of the US health personnel, receive 67,965 dollars annually.

According to the data in Table 4, the largest income among specialties physician in OECD is paid in Ireland but the lowest income is in Mexico. Among OECD coun-

Table 1. The means monthly income for the groups of specialists before and after the new tariff and the percentage of changes in 2016 (Source: financial affairs of IUMS)

\begin{tabular}{lcccc}
\hline Specialties & Samples & $\begin{array}{c}\text { The mean income } \\
\text { during the first } 6 \\
\text { months }\end{array}$ & $\begin{array}{c}\text { The mean income } \\
\text { during the second } 6 \\
\text { months }\end{array}$ & $\begin{array}{c}\text { Change percentage } \\
\text { ENT }\end{array}$ \\
Emergency medicine & 14 & $157,340,220$ & $212,850,355$ & $35 \%$ \\
Anesthesia & 14 & $65,416,667$ & $73,125,156$ & $\% 11$ \\
Gynecologist & 13 & $190,297,589$ & $251,139,376$ & $32 \%$ \\
Gastroenterology & 10 & $64,320,143$ & $138,247,549$ & $115 \%$ \\
Pediatrics & 10 & $46,063,996$ & $116,611,598$ & $153 \%$ \\
Orthopedic & 10 & $33,666,667$ & $70,049,846$ & $120 \%$ \\
Cardiology & 10 & $19,080,198$ & $38,598,456$ & $101 \%$ \\
Surgery & 10 & $84,293,500$ & $107,350,000$ & $27 \%$ \\
Neurology & 10 & $120,207,134$ & $310,225,318$ & $160 \%$ \\
Neurosurgery & 10 & $154,569,231$ & $192,466,053$ & $24 \%$ \\
Internal medicine & 7 & $175,569,690$ & $236,750,490$ & $35 \%$ \\
Ophthalmology & 10 & $38,000,000$ & $108,031,092$ & $184 \%$ \\
Sport medicine & 5 & $249,589,425$ & $270,856,432$ & $8 \%$ \\
Nurses & 100 & $75,865,382$ & $104,365,421$ & $37 \%$ \\
\hline
\end{tabular}

\begin{tabular}{|c|c|c|}
\hline Specialist physicians & Before & After \\
\hline$\overline{E N T}$ & 14 & 14 \\
\hline Emergency medicine & 6.2 & 4.8 \\
\hline Anesthesia & 18 & 16 \\
\hline Gynecologist & 6 & 9 \\
\hline Gastroenterology & 4.3 & 7.7 \\
\hline Pediatrics & 3.2 & 4.6 \\
\hline Orthopedic & 1.8 & 2.5 \\
\hline Cardiology & 8 & 7 \\
\hline Surgery & 11.4 & 20 \\
\hline Neurology & 14 & 12.8 \\
\hline Neurosurgery & 16.6 & 15.6 \\
\hline Internal medicine & 3.6 & 7 \\
\hline Ophthalmology & 23.7 & 17.8 \\
\hline Sport medicine & 7.1 & 6.88 \\
\hline Overall & 9.8 & 10.4 \\
\hline
\end{tabular}

Table 2. Ratio of each physician's income as opposed to nursing group 


\begin{tabular}{lc} 
Table 4. Medical physicians and nurses' income per capital (yearly) in the US \\
\hline Type of specialty & Income per capita in the US (US Dollar) \\
\hline Internal medicine & 183,290 \\
General practitioner & 131,851 \\
Pediatrics & 149,131 \\
Neurology & 204,644 \\
Orthopedics & 355,545 \\
Anesthesia & 269,612 \\
Emergency medicine & 207,318 \\
Cardiology & 225,656 \\
Gastroenterology & 297,656 \\
Gynecologist & 204,563 \\
Trauma surgeon & 310,641 \\
Sport medicine & 184,217 \\
RN nurse & 67,965 \\
\hline
\end{tabular}

tries, the lowest specialist physician's earnings belong to Belgium, Czech Republic, and Mexico respectively.

Moreover, the largest income for nurses among OECD belongs to Luxembourg, Ireland, Norway, and England. Belgium, Czech Republic, Turkey, and Mexico are among OECD countries that pay the lowest income for nursing groups.

The largest Ratio of physicians' average income compared to nurses' income belongs to Ireland, Turkey, and the Netherlands, whereas countries such as Mexico, Norway, and the Czech Republic have the lowest Ratio of physician income to nurse income. On average, physicians' income is 2.4 times more than that of nurses in OECD countries. In comparison to Iran, this ratio is mean- ingfully lower than 9.8 (before the New Tariffs Book) and 10.4 (after the implementation of the New Tariffs Book), which indicates lack of proportionality between physicians and nursing groups' income in Iran.

Based on the World Bank report, GDP per capita in Iran in 2014 was equivalent to 5936, 54 US dollars that reaches to 16507 dollars when adjusted based on PPP. Given dollar price equivalent of Rials in Iran in 2014, income per capita was equivalent to $189,552,000$ Rials. As shown in Table 5 Before the New Tariffs Book, the highest ratios of specialist physicians' income to GDP per capita belonged to ophthalmology with 15.7 times, neurosurgery with 11 times, anesthesia with 12 times and ENT with 9.9 times. That is, an anesthesia physician, for instance, has been

Table 3. Specialist physician and nurses' average income (US Dollar) in OECD

\begin{tabular}{|c|c|c|c|c|}
\hline Country & Specialist physicians & General practitioners & Nurses & Proportion of physician earnings to nurses \\
\hline Luxembourg & 170,000 & 115,000 & 80,000 & 2.125 \\
\hline Ireland & 190,000 & - & 54,000 & 3.51 \\
\hline England & 120,000 & 90,000 & 52,000 & 2.3 \\
\hline Turkey & 80,000 & 40,000 & 24,000 & 3.33 \\
\hline Slovenia & 80,000 & 70,000 & 35,000 & 2.28 \\
\hline Norway & 80,000 & - & 50,000 & 1.6 \\
\hline New Zealand & 105,000 & 70,000 & 47,000 & 2.23 \\
\hline Netherlands & 145,000 & - & 44,000 & 3.29 \\
\hline Mexico & 45,000 & 38,000 & 26,000 & 1.73 \\
\hline Italy & 95,000 & - & 37,000 & 2.56 \\
\hline Israel & 95,000 & 55,000 & 43,000 & 2.2 \\
\hline Iceland & 95,000 & 100,000 & 42,000 & 2.26 \\
\hline Belgium & 35,000 & 33,000 & 15,000 & 2.33 \\
\hline Germany & 90,000 & 90,000 & 42,000 & 2.14 \\
\hline Finland & 100,000 & 70,000 & 37,000 & 2.7 \\
\hline Czech Republic & 39,000 & - & 20,000 & 1.95 \\
\hline Mean & & & & 2.4 \\
\hline
\end{tabular}

Table 5. Ratio of physician and nurses' average income to GDP per capita before and after the new tariff book

\begin{tabular}{lcc}
\hline Specialty type & Before & After \\
\hline ENT & 9.9 & 13.4 \\
Emergency medicine & 4.1 & 4.6 \\
Anesthesia & 12 & 15.8 \\
Gynecologist & 4 & 8.7 \\
Gastroenterology & 2.9 & 7.3 \\
Pediatrics & 2.1 & 4.4 \\
Orthopedics & 1.2 & 2.4 \\
Cardiology & 5.3 & 6.7 \\
Surgery & 7.5 & 19.5 \\
Neurology & 9.7 & 12.1 \\
Neurosurgery & 11 & 14.9 \\
Internal medicine & 2.4 & 6.8 \\
Ophthalmology & 15.7 & 17 \\
Sport medicine & 4.8 & 6.5 \\
Mean of all physicians & 7 & 11 \\
Nurse & 0.66 & 0.95 \\
\hline
\end{tabular}


Table 6. Comparison of average income by specialty in Iran and the US

\begin{tabular}{lcc}
\hline Specialty type & Average income per capita in the US & Average income per capita in Iran \\
\hline Internal medicine & 183,290 & 99,692 \\
General practitioner & 131,851 & NA $^{1}$ \\
Pediatrics & 149,131 & 64,615 \\
Neurology & 204,644 & 217,846 \\
Orthopedics & 355,545 & 35,621 \\
Anesthesia & 269,612 & 231,692 \\
Emergency medicine & 207,318 & 67,495 \\
Cardiology & 225,656 & 99,092 \\
Gastroenterology & 297,656 & 107,640 \\
Women medicine & 204,563 & 127,606 \\
Trauma surgeon & 310,641 & 286,153 \\
Sport medicine & 184,217 & 96,332 \\
RN nurse & 67,965 & 13,993 \\
\hline
\end{tabular}

paid 12 times as GDP per capita as after the implementation of the new tariff book. The lowest proportions of specialist physicians' income to GDP per capita were for orthopedics, pediatrics and internal medicine. The proportion of average nurse income to GDP per capita was equal to 0.66 ; showing an income less than GDP per capita.

After the new tariff book, the highest ratios of specialist physicians' income to GDP per capita belonged to ophthalmology, neurosurgery, and anesthesia. However, the lowest proportions are among orthopedics, pediatrics, and internal medicine. The proportion of average nurses' income to GDP per capita was equal to 0.99 after the book. As a whole, before and after implementing the new tariff book, the proportion of specialist physicians' income to GDP per capita has increased, on average, by 7 and 11 times respectively.

Income of physicians and nurses in Iran and in the United States after adjusting it based on PPP

Since the income of various countries cannot be compared due to discrepancies in currencies and PPP, the only way of comparing specialist physicians' income is to adjust them based on PPP. Since average dollar rate to Rials was 32510 in 2014, and the purchasing power of one dollar in Iran is 2.5 times as much as that in the US, incomes by Rials in Iran were converted into dollars and represented in Table 6. As shown in Table 6, after adjusting incomes based on PPP, the only specialty in Iran with more income than that in the US belonged to neurology. The other medical specialty in Iran, which its income is close to the one in the United States is the Trauma Surgery with an annual income of \$286,153, and \$ 310,641 in Iran and the US respectively. Anesthesia is another specialty that its earnings are close together in both countries. This specialty is paid \$ 231692 in Iran but \$ 269612 in the US.

The largest income inequality between two countries after adjusting incomes by PPP was observed in orthopedics, cardiology, and gastroenterology specialties. Nursing groups earn $\$ 13.993$ in Iran which is about one fifth of the US, $\$ 67,965$ annually.

An important issue which can be concluded from Table 6 is the gap between specialist physicians and nursing groups' incomes in these countries. Whilst a physician income in the US is about 5 times (in the worst case) greater than a nurse's income, the same proportion in Iran is about 10 times and more; even in some cases 20 times as much as nursing groups' income.

\section{Discussion}

Given the requirement of monitoring and evaluating the effect of the new tariff book on incomes of relative medical specialties and nursing groups, this study aimed to examine the changes in their incomes in the form of a before-after analysis and to compare their incomes with those of the selected countries. Studies indicate that in Iran, a large part of the health sector's expenditures has been dedicated to pay for human resources, particularly physicians (8). One of the major implications of establishing the new tariff book was to increase healthcare services tariffs to narrow the gap between services tariffs and their real costs and to remove unlawful (under the table) payments. As the results implied, there were increases in the incomes of different medical specialties after the implementation of the new tariff book. The other conclusion drawn from this study is related to the gap between incomes of specialist physicians to nursing groups. Such an income gap is subject to discussion. The income gap between these two strata cooperating jointly and continuously has a direct and dramatic effect on the effectiveness of treatment; hence, this problem should be solved by officials as quickly as possible (18). However, the shortage of nursing staff according to officials is one of the serious current challenges Iranian healthcare system faces $(13,14)$.

Therefore, it seems that a policy to equalize earning of this stratum accounting for almost $50 \%$ of the human resources of the health care staff could be a motive for especially young people to be employed and study in this scope. The income gap between specialist physicians and nurses is common in most countries depending on economic and healthcare systems. But how much this income gap is, in Iran matched to other countries, remains controversial (19).

On the basis of our findings, before the implementation of the New Tariffs Book, the mean income of specialist physicians was 9.8 times as much as a nursing group, but this figure has run to 10.8 times after exercising New Tariffs Book.

From the results found in this study and similar studies conducted in African countries by McPake et al. (16), the data available on the Payscale website of the United States and the study of the MGMA Institute (17) as well as studies done by OECD Health Data; following arguments de- 
serve to be mentioned:

1. There was a wide and significant difference in specialist physicians' income vis-à-vis nursing groups' income before and after establishing the new book. In contrast, specialist physicians in African countries receive income by 3-4 times, in OECD countries 2.4 times and in the US 3-4 times as much as nursing groups do.

2. By establishing the New Tariffs Book, the income gap between specialist physicians and nursing groups not only has not declined but also increased slightly.

As outlined before, in the US, an average of specialist physicians' income is 3.5 times as much as that of nursing groups. Such an income gap in the US is bigger than that of the OECD countries. In contrast, in Iran, the Ratio of specialist physicians' to nursing groups' income is 10 and more; implying that this ratio in Iran is more inequitable than OECD, the US, and African countries.

Generally, before and after establishing the new tariff book, the proportion of specialist physicians' income to GDP per capita has increased by 7 and 11 times respectively which suggests an explosive growth in specialist physicians' income level. Although, the ratio of a nurse average income to GDP per capita has increased from 0.66 before to 0.99 after the book, this increase is less than that of specialist physicians. Reports without scientific basis on comparing incomes of specialist physicians in Iran with those in the US encouraged us to carry out a study like this and compare the income level regarding PPP in both countries. The only specialty in Iran having more income than that in the US belongs to neurology. Whereas other medical specialties have lower PPP- adjusted income in Iran than those in the US. PPP-adjusted incomes of nursing groups are equivalent to 13,993 and 67,965 dollars in Iran and the US, respectively.

\section{Limitations}

Lack of access to required data due to sensitivity to income disclosure not also for physicians and nurses but also for all working groups.

\section{Conclusion}

An important conclusion which can be drawn from the present study is the gap generated between specialist physicians and nursing groups' incomes in these countries. Whilst the physician income in the US is about 5 times (in the worst case) greater than nursing groups incomes, whereas, the same proportion in Iran is about 10 times and more, even in some cases 20 times of nursing groups' income.

If Iranian health system is to be placed into the right path of health and socio-economic development, it seems necessary to apply other countries' experiences and their theories with respect to Iran specific circumstances and accurate measurements of the advantages and disadvantages of policies being implemented. Getting familiar with the experience of different countries can specify to what extent the distribution of income among specialist physicians and nurses concerning the severity of work, stress, and educational qualifications and other incomerelated factors is equitable. Finally, by determination of income bottom and ceiling for specialist physicians, nursing groups, and other hospital staff the income gap can be reduced which in turn this plays a pivotal role in effectively providing quality services to customers.

\section{Acknowledgment}

The authors would like to express their gratitude to the financial management of IUMS for providing access to the relevant data and Health Management and Economics Research Center for this study and those who helped us to conduct a study like this.

\section{Conflict of Interests}

The authors declare that they have no competing interests.

\section{References}

1. Andreassen L, Di Tommaso ML, Strom S. Wages Anatomy. Labor supply of nurses and a comparison with physicians. 2014.

2.Peters DH, Garg A, Bloom G, Walker DG, Brieger WR, Hafizur Rahman M. Poverty and access to health care in developing countries. Ann N Y Acad Sci. 2008;1136(1):161-71.

3. Doshmangir L, Rashidian A, Akbari Sari A. Unresolved issues in medical tariffs: Challenges and respective solutions to improve tariff system in Iranian health sectors. Hospital Journal. 2011;10(4):2-10.

4. Zare H, Akhavan B, Azadi M, Masoudi asl E, et al . Methods for determination of tariffs for medical services in developed countries and suggests a model for Iran. Parliament Strat. 2013;20(74):5-34

5. Zare Bidaki GA. Comparison of General Physician Income Throughout the World. Mashd University. 2013:5.

6. Jafari M, Rashidian A, Abolhasani F, Mohammad K, Yazdani S, Parkerton P, et al. Space or no space for managing public hospitals; a qualitative study of hospital autonomy in Iran. Int J Health Plann Manage. 2011;26(3):e121-e37.

7. Health Mo. The relative value of health care services in the Islamic Republic of Iran: Ministry of Health; 2014. 523 p.

8. Tarighat MH, Hassanzadeh A, et al . Principles of the National Health Policy (comparative study). Social Studies council, Iranian Islamic Parliament Research Center; 2008.

9. Tofighi S. Designing a model for medical tariff in governmental and non- governmental sectors. Tehran: Ministry of Health, Functional Researches Secretariat. 2007.

10. Van Doorslaer E, Masseria C and the OECD Health Equity Research Group Members . Income-related inequality in the use of medical care in 21 OECD countries: OECD Paris; 2004.

11. Kantarevic J, Kralj B. Link between pay for performance incentives and physician payment mechanisms: evidence from the diabetes management incentive in Ontario. Health Econ. 2013;22(12):1417-39.

12. Pourreza A. Health economics: Areas and perspectives. Payesh. 2003;2(4):297-302

13. Jariani A. Shortage of 250 thousand nurses in the country. In: News A, editor. Iran 2014.

14. Paidari R. The biggest challenge of shortage of nurses 95: 1300 missing nursing workforce. Iran 2016.

15. Johson jp. Salary Trends Among Medical Professionals:1998 - 2013 USA: Economic Research Institute; 20132013.

16. McCoy D, Bennett S, Witter S, Pond B, Baker B, Gow J, et al. Salaries and incomes of health workers in sub-Saharan Africa. The Lancet. 2008;371(9613):675-81.

17. Association MGM. MGMA Physician Compensation and Production Survey: 2014 Report Based on 2013 Data. Report. USA: MGMA, MGMA; 20142014.

18. Nguyen Le TA, Lo Sasso AT, Vujicic M. Trends in the earnings gender gap among dentists, physicians, and lawyers. J Am Dent Assoc (1939). 2017 Apr;148(4):257-62.

19. McCartney M. Margaret McCartney: Publishing doctors' private earnings is not enough. BMJ (Clinical research ed). 2016 Oct 4;355:i5370. 